\title{
Addressing Stigma and Discrimination Towards Mental Illness: A Community Based Intervention Programme from India
}

\author{
Soyuz John' ${ }^{1}$ R. Muralidhar ${ }^{1}$ K. Janaki $\operatorname{Raman}^{2} \cdot$ B. N. Gangadhar ${ }^{3}$
}

Received: 7 March 2015 / Accepted: 17 June 2015/Published online: 23 July 2015

(C) Springer India Pvt. Ltd. 2015

\begin{abstract}
Persons with mental illness experience discrimination due to the stigmatizing attitudes of the society. Desired social distance was greater for the person depicted in the psychosis, and the main predictor of greater social distance was perceiving the person as dangerous. In India men with schizophrenia reported being unmarried, hid their illness in job applications and from others, and experienced ridicule and shame. They reported that their experience of stigma was most acute at their places of employment. Women reported experiences of stigma in relation to marriage, pregnancy, and childbirth. The current paper narrates a step model community-based intervention programme that was attempted to reduce stigma prevailed in the community towards persons affected with mental illness and their family. Four members affected with mental illness from a family were reported to the psychiatric hospital with the help of a voluntary organization. Four of them were suffering from chronic schizophrenia and malnutrition. Psychiatric social work team made use of Home Visit, Family Burden Schedule and Stigma Questionnaire to assess the family condition. The assessments revealed that the family was facing serious discrimination in the village; neighbours were not coming home, children threw stones to the home and people considered the family was under the attack of evil
\end{abstract}

Soyuz John

soyuzjohn@gmail.com

1 Department of Psychiatric Social Work, National Institute of Mental Health and Neuro Sciences (NIMHANS), Bangalore, Karnataka, India

2 Shanthivanam Trust, Trichy, Tamil Nadu, India

3 Department of Psychiatry, National Institute of Mental Health and Neuro Sciences (NIMHANS), Bangalore, Karnataka, India spirits. All the family members were deprived of their basic needs like food, water and social living. Other than giving hospital-based treatment for the family members affected with mental illness, availing disability benefits, and rehabilitating the persons, the psychiatric social work team organized one day community-based intervention programme targeting knowledge and attitude of community members towards mental illness. The key elements of community-based intervention were home visits, one to one interaction, collaborative work with local governing bodies, street play, experience sharing by a person affected with mental illness, display and distribution of IEC material, interactive sessions and oath taking. The community-based intervention could bring changes in the stigma, reduced discrimination and increased social acceptance and social support of the family members.

Keywords Mental illness - Stigma - Discrimination · Community-based intervention

\section{Introduction}

Schizophrenia is a severe mental illness characterized by chronic or relapsing symptoms [1]. It is amongst the top ten leading causes of disability world-wide, resulting in enormous economic and social costs for families and public health systems [2]. Schizophrenia is a debilitating mental illness that has a significant impact not only in the patient but also in the entire family as well [3]. Taking care of patients with schizophrenia is a major source of burden to the family [4-6]. People with mental disorders experience discrimination as a consequence of stigmatizing attitudes that are largely socio-culturally constructed. Stigma has been defined as a negative attitude, based on prejudice and 
misinformation, which is triggered by a marker of an illness [7]. The World Health Organization has described stigma as the greatest impediment to the provision of effective mental healthcare in the community setting [8]. Desired social distance was consistently greater for the person depicted in the psychosis, and the main predictor of greater social distance was perceiving the person as dangerous [9]. In India men with schizophrenia reported being unmarried, hide their illness in job applications and from others, and experienced ridicule and shame. They reported that their experience of stigma was most acute at their places of employment. Women reported experiences of stigma in relation to marriage, pregnancy, and childbirth [10]. Another study from India reported that person affected with mental illness felt high internalized stigma. Apart from treatment in community-based care, unemployment, absence of long-term friendships, no hope of cure with medication, presence of other illnesses, and substance use were significantly associated with high internalized stigma [11].

As WHO rightly pointed out, stigma prevailing in community and the perceived stigma of persons affected with mental illness are greatest hindrances for the delay in treatment-seeking, treatment continuing and reintegration to the society. Persons affected with mental illness who are progressing toward recovery should have the feeling of hope, de-stigmatization, empowerment, self-acceptance, insight, awareness, collaboration with professionals, sense of autonomy and self-control [12]. Stigma is an interruption for treatment seeking and recovery as well.

There were many attempts made by mental health professionals to reduce the social stigma against person affected with mental illness (PAMI). Community based work-place education for community people, PAMIs and their care givers found to be effective in reducing stigma related knowledge and attitudes of the participants [13]. Anti-stigma education programme for police personnel brought changes in their changing attitudes, mental health literacy and intentional behaviour [14]. A systematic review stated that classroom based interventions are effective in correcting stigma related belief of children and adolescents [15].

Recently, there have been developments of a number of diagrammatic 'models' bearing on community intervention programmes. There have been two basic types, one involving actual or hypothetical causal relationships (effect, or how-it-works models) and the other, sequences of activities or events (stage, or how-to-do-it models) [16]. Stage models for health promotion programmes imply an ordered or cyclical set of activities, in which preparation is followed by implementation, maintenance, evaluation and revision. In each stage, the importance of effective community participation is recognized and purpose, action and information needed have to be specified [16]. The aim of this paper is to illustrate how the stage model of community intervention programme was found to be effective in addressing stigma and discrimination about mental illness in the community through a single case study model.

\section{Method and Process}

\section{Case Example}

In 2012, a voluntary organization brought four persons to a psychiatric hospital for treatment. An interesting as well as distressing fact was that those four of them were from a single family. Initial appearance of the persons was really pathetic, because, all of them were starving for many days and all of them looked tired and lethargic. Before initiating psychiatric assessment and interventions, all of them were admitted in Intensive Care Unit for emergency interventions. Psychiatric treatment team assessed and diagnosed them with Chronic Schizophrenia. Initially eldest son started showing psychiatric symptoms in the form of muttering and smiling to self, withdrawn behaviours and suspiciousness. Later mother developed almost similar kind of symptoms. Then two daughters also had similar symptoms. All of them had suspiciousness and their social interaction significantly got reduced. They became hostile to the neighbours and they gave least attention to the family. Self-care of these persons deteriorated, they wore shabby dresses and never took bath properly. After the onset of the illness, two of them stopped going for job which reduced the income of the family. The youngest brother was unable to meet all the demands of the family members. Subsequently the family started starving. Once the treatment was initiated, the multi-disciplinary treatment team, decided to explore further about the case (Fig. 1).

\section{Assessment}

Home visits, Family Burden Schedule (Pai \& Kapur) and questionnaire adopted from World Health Organization Family Interview Schedule stigma items were used to gather further information about the family. A semistructured Home Visit Form was developed for documenting the observations during the home visits. Major areas of the Home Visit Form were; Home Environment (Strength of physical space, challenges in terms of physical space, resources to meet physical and emotional needs, presence and roles of extended family, communication pattern both verbal and non-verbal), Neighbourhood Environment (Strength of the location, challenges in terms of safety, resources for formal and informal support, interaction, attitude) and Social Environment 
Fig. 1 Family Tree and Living Arrangements

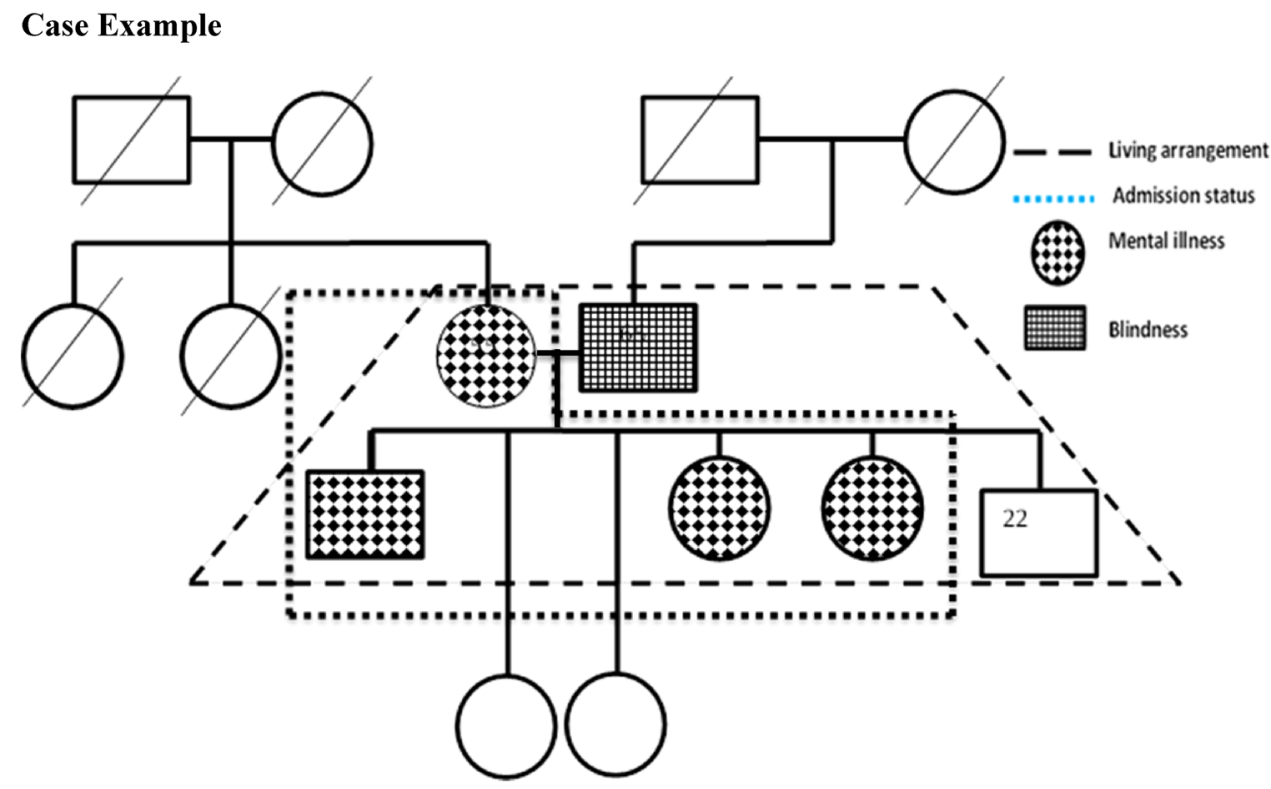

(social attitude, absence/presence of discrimination \& stigma, availability of support).

Family Burden Schedule [17] was administered to find out the burden of the family. It has three point rating (sever burden $=2$, moderate burden $=1 \&$ no burden $=0$ ) and has six subdomains (financial burden, disruption of routine family activities, disruption of family leisure, disruption of family interaction, effects on physical health of others and effects on mental health on others). The total score of caregiver burden was calculated by summing up the individual items $(0=$ minimum $50=$ maximum $)$. Higher the score indicated higher the care giver burden.

Data regarding stigma collected from the brother using a questionnaire adopted from World Health Organization Family Interview Schedule stigma items. There were fourteen items questionnaire included items like the need to hide the patients' mental illness status, feeling of shame and embarrassment, and avoidance of social gatherings and friendships. The responses were rated in a four point scale $(0=$ not at all, $1=$ sometimes, $2=$ often, $3=a$ lot $)$. Total score of stigma was calculated by adding up individual items $(0=$ minimum, $42=$ maximum $)$. Higher score showed higher stigma.

\section{Findings}

The social work team involved in the treatment process of the cases made a home visit to the family. The home visit gave lot more information about the family, neighbourhood and the social condition. The family was from a rural background of Karnataka in India. The family belonged to below poverty line. They had a small home. The parents had six children; four girls and two boys.
Two girls were got married and they were staying separately with their respective husbands in far-away villages. They rarely visited the family and their husbands kept distance from the family. Father lost his eye-sight for years and needed assistance for moving around. Youngest son who was 22 years of age was the bread winner for the family. He had a job in an 'agarbathi' factory. Initially eldest son and another daughter were going for kooli work but once illness affected them they stopped going for it.

The neighbours believed that the family was affected with 'evil spirit'. They also believed that person associating with the family might also have the bad consequence. Children in the neighbourhood threw stones, giggled at them and chased them away. The team also visited the local governing body members (Panchayat Authorities). They were unaware about the condition of the family.

Mental illness of the members ruptured the interaction pattern in the family. They suffered serious food scarcity, health issues, financial burden and the youngest brother was under significant burden and stress. The family lacked secondary and tertiary support. They experienced high level of social exclusion and rejection. The villages considered the family as a sign of curse.

Before initiating the community based intervention, the Family Burden Schedule was administrated to the last sibling. He scored forty (40) out of fifty (50) in the scale which indicated the family was experiencing high burden due to the illness of the family members. Stigma item questionnaire was given to the same person. He got thirty one (31) out of forty (40) in the scale which again evidenced that the family was facing significant stigma and discrimination in the neighbourhood and society. 


\section{Community Based Intervention}

The psychiatric hospital provided acute treatment to the family members and they responded well to the anti-psychotic medicines. The psychiatric social work team decided to conduct a community awareness programme in the village of the family. Stage model of community intervention programme was followed. Existing stage models for health promotion programme implied an ordered or cyclical set of activities, in which analysis is followed by planning, implementation, evaluation and revision. The diagrammatic representation of the intervention is given below (in Fig. 2).

\section{Analysis}

The treating team especially social workers' team made initial assessment about each family members, their neighbours and the community through observation, interviews and interaction with the youngest brother, voluntary organizations and home visit and community visit. A psychiatric social work team comprised of twelve members visited the village for the second time. The team divided into six small groups and visited almost all the houses in the village. The major objectives of the visits were to have an informal assessment about the knowledge and attitude of the villages about mental illness and to invite them for the community awareness programme. The villages were not having adequate information about mental illness, symptoms, causes and treatment. They considered mental illness as the sign of curse and attack of evil spirit.

\section{Planning}

The team discussed the programme schedule with the other multi-disciplinary team members, sort permission from the concerned department, from the Director of the institute and from local governing authorities of the village. Interaction with key informants like local governing body members gave clarity about the dates and mode and medium of language for the programme. Major objectives of the programme were to educate the villagers about mental illness and to reduce the prevailing stigma in the community. Psychiatric social work team invited other social workers from the department and conducted a detailed discussion to schedule the entire programme. In the discussion, date, timing, types and nature of programme and source of budget were finalized.

The team mobilized fund from the various sources for the community awareness programme and the fund was used for the same. Details of the source of money and expenditure were submitted to the institution, to the persons and organization contributed into the fund. Family members were informed about the programme and they gave consent to carry out the intervention in their community.

\section{Implementation}

The tertiary care psychiatric hospital had education materials specifically developed for community awareness programme. The education material had pictures and written informations about mental illness, symptoms,
Fig. 2 Stage Model of Community Intervention Programme

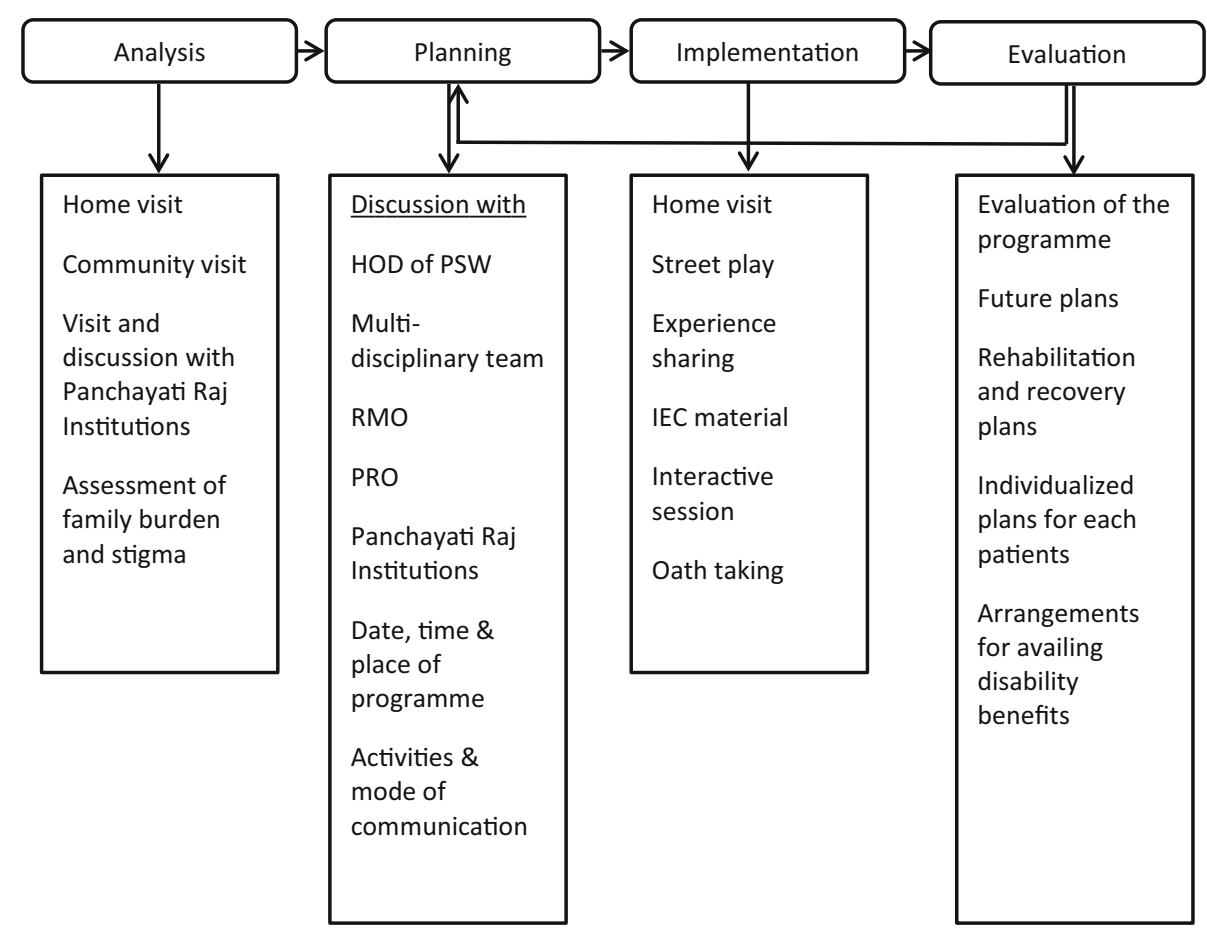


causes and treatments. Those IEC (Information, Education \& Communication) materials were displayed in and around the premises of the villages and at the meeting places. All villagers were invited to the venue arranged for the programme.

After the inauguration by the Panchayat president, the psychiatric social work team enacted a psycho drama. The short drama described the story of a middle aged man. $\mathrm{He}$ was a responsible, calm and gentle-man, who was regular to work and responsibilities and looked after his family well. Gradually he became withdrawn, less talkative and hostile to family members and to the outsiders. He started talking and smiling to self and displayed meaningless gestures. Initially family was confused and worried about the changes in the person. The family tried magico-religious treatment, but the person remained the same. Later the family took the person to a hospital. The doctor in the hospital identified the condition of the person, educated the family about mental illness and referred him to a psychiatric hospital. The person underwent one month of treatment and completely recovered from the condition. Gradually he started going for job and lead a pleasant family life. The drama communicated the common symptoms of mental illness, myths and mis-concepts about mental illness, need for proper treatment and long term medication and possibility of recovery.

A person affected with schizophrenia and recovered with treatment expressed willingness to share his experiences. He shared his life experiences with mental illness. He was a software engineer. He earned a good amount of money, had wife and two children. Gradually he started hearing some voices telling him that all his family members, relative and co-workers were his enemies and they were plotting against and conspiring against him. The voices warned him to beware of their activities. Then the person became hyper vigilant, suspected every act and words of the people around him. He started suspecting every one and behaved hostile to everybody. He stopped his job spent most of the time at home. Then the family members took him to a hospital and he underwent treatment. Few weeks after the treatment, the voice stopped talking to him, his fearfulness and suspiciousness remitted and he realized that all those feeling and perceptions were not real and were parts of his mental illness. He continued taking medicines, rejoined for work, maintained good interpersonal relationship with family members, relatives and co-workers.

Before the concluding session, villagers were allowed to interact with the mental health team and were given time to clarify their doubts. Addresses and phone numbers of available treatment and rehabilitation centers were given to them. Available welfare benefits for person with mental illness and procedures to avail those benefits were explained to the villagers.
In the concluding session, all the villagers and organizing team took an oath for prevention, treatment and promotion of mental health of selves and others. All of them hold hand together and tied a knot on each other's' hand which symbolically expressed the willingness to work together for the mental health of the individuals in the community.

\section{Outcome}

The family members admitted in the hospital showed symptom wise improvement within one month of In-patient care. They were shifted to a half-way home for three months. They underwent social skill training and vocational training. Later they went to their home. The psychiatric social work team made another home visit to see the condition in the home. Family Burden Schedule and Stigma Questionnaire were administered again to the last sibling to see any changes he and his family felt in the community.

Routine family activities, family leisure and family interaction are the major areas where the family felt decrease of burden in the post assessment. Finance remained a major source of burden even in the post assessment. Family felt significant reduction in the stigma and discrimination they experienced in the society. In the stigma scale, worries about neighbours treat them differently, worries that others will find out about illness, worries that neighbours and friends would avoid them and worries about taking the family members out were some of the areas where family felt better in the post assessment. The family experienced better acceptance in the community. The family was able to build-up and maintained adequate interpersonal relationship with the neighbours. Local governing authority was supportive and they initiated the procedure for availing disability benefits for the family members who were affected with mental illness. The team visited the tailoring center where one of the daughters used to work. They were ready to take her back once she got prepared for the job (Fig. 3).

Currently the family members come regularly for follow ups and take medicine properly. One daughter started working in the tailoring shop and is earning for the family. Disability benefits are available for the family.

\section{Discussion}

Large numbers of persons with psychiatric problems do not attend any health facility due to lack of awareness about treatment services, the distance, and due to the fear of the stigma associated with treatment [18]. People with mental disorders experience and faces discrimination as a 


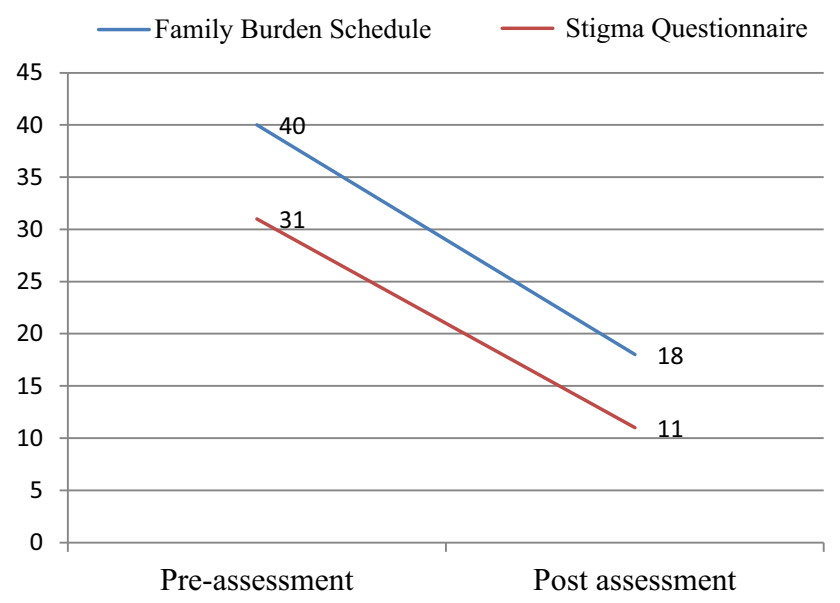

Fig. 3 Comparison of family burden and stigma scores between pre and post assessment

consequence of stigmatizing attitudes that are largely socio-culturally constructed and promoting bio-medical explanations for mental disorders may exacerbate discriminatory attitudes. So contextually relevant mental health training and programme are able to communicate and develop more positive attitudes in community [9]. In the first phase of the current community based intervention, the team made home visits, assessed knowledge, beliefs and attitudes of the villages and intervention was planned and tailor made accordingly. The current study, as evidences showed, attempted a cultural and contextual based community based intervention and could bring favorable and positive changes in the villagers towards mental illness.

Social contact intervention found to be effective in reducing stigma on a mass level. Examples of social contacts were football matches, dance workshops, leisure centers day, oath taking and self-disclosure of personal experiences with mental health problems. These events increased the opportunities to social interaction between persons with mental illness and persons with-out mental illness and found to be effective in reducing stigma related to mental health problems [19]. The current community based intervention also utilized multiple social contacts methods like home visits, self-disclosure by person experienced mental health problems, direct face-to-face interactions and oath taking. The intervention was not only cultural specific but could adapt evidence based methods as well.

Stage model is a widely used frame work of for intervention. It clearly explains each stage of intervention and activities needed to carry out at each stages of intervention [20]. Stage model is a simple and effective model for carrying out community based intervention. In the current paper, the model was found to be effective in implementing intervention addressing stigma and discrimination towards mental illness. Situation specific and culturally oriented interventions are more appropriate for community level interventions [9]. Initial phases of stage model (Analysis and Planning) allow us to understand the needs and formulate tailor-made intervention for the targeted population.

\section{Limitation}

The paper failed to quantify and report the knowledge and attitude of the community members towards mental illness. The local governing members of the community advised the team not to attempt for any formal assessment with community members. Formal structured assessment might trigger suspicion and resistance in the community towards the programme.

\section{Conclusion}

Public stigma against person with mental illness and family members of person with mental illness is a serious hindrance to treatment and recovery. The case of the four family members is an example of sheer discrimination and marginalization against person affected with mental illness. The psychiatric social work team could identify it and could manage it to a greater level. This experience gives us a lesson that effective contextual and evidence based community intervention can reduce public stigma to a larger extend. Psychiatric social workers have important role in preventing and promoting mental health of the community. Identifying, assessing and addressing psycho social aspect of mental health problem will help the person in the road to recovery and accelerate the speed of the journey to recovery.

\section{Compliance with Ethical Standards}

Conflict of interest The authors declare that they have no conflict of interest.

\section{References}

1. Thara R, Henrietta M, Joseph A, Rajkumar S, Eaton WW. Tenyear course of schizophrenia-the Madras longitudinal study. Acta Psychiatr Scand. 1994;90(5):329-36.

2. Grover S, Avasthi A, Chakrabarti S, Bhansali A, Kulhara P. Cost of care of schizophrenia: a study of Indian out-patient attenders. Acta Psychiatr Scand. 2005;112(1):54-63.

3. Caqueo-Urizar A, Miranda-Castillo C, Lemos Giraldez S, Lee Maturana SL, Ramirez Perez M, Mascayano Tapia F. An updated review on burden on caregivers of schizophrenia patients. Psicothema. 2014;26(2):235-43. 
4. Chaturvedi SK, Hamza A, Sharma MP. Changes in distressing behavior perceived by family of persons with schizophrenia at home-25 years later. Indian journal of psychological medicine. 2014;36(3):282-7.

5. Jagannathan A, Thirthalli J, Hamza A, Nagendra HR, Gangadhar BN. Predictors of family caregiver burden in schizophrenia: study from an in-patient tertiary care hospital in India. Asian journal of psychiatry. 2014;8:94-8.

6. Kumar CN, Suresha KK, Thirthalli J, Arunachala U, Gangadhar BN. Caregiver burden is associated with disability in schizophrenia: results of a study from a rural setting of south India. Int J Soc Psychiatry. 2014;61(2):157-63.

7. Sartorius N. Iatrogenic stigma of mental illness: begins with behaviour and attitudes of medical professionals, especially psychiatrists. BMJ : British Medical Journal. 2002;324(7352): 1470-1.

8. World Health Organization[Internet]. Europe: World Health Organization regional office for Europe (2015). http://www.euro. who.int/. Accessed 3 Jan 2015.

9. Kermode M, Bowen K, Arole S, Pathare S, Jorm AF. Attitudes to people with mental disorders: a mental health literacy survey in a rural area of Maharashtra, India. Soc Psychiatry Psychiatr Epidemiol. 2009;44(12):1087-96.

10. Loganathan S, Murthy RS. Living with schizophrenia in India: gender perspectives. Transcult Psychiatry. 2011;48(5):569-84.

11. James TT, Kutty VR. Assessment of Internalized Stigma Among Patients With Mental Disorders in Thiruvananthapuram District, Kerala, India. Asia-Pacific journal of public health/Asia-Pacific Academic Consortium for Public Health. 2014.

12. Liberman RP, Kopelowicz A. Recovery from schizophrenia: a concept in search of research. Psychiatr Serv (Wash DC). $2005 ; 56(6): 735-42$.
13. Blignault I, Woodland L, Ponzio V, Ristevski D, Kirov S. Using a multifaceted community intervention to reduce stigma about mental illness in an Australian Macedonian community. Health Promot J Aust. 2009;20(3):227-33.

14. Hansson L, Markstrom U. The effectiveness of an anti-stigma intervention in a basic police officer training programme: a controlled study. BMC Psychiatry. 2014;14:55.

15. Mellor C. School-based interventions targeting stigma of mental illness: systematic review. Psychiatr Bull. 2014;38(4):164-71.

16. Sanderson C, Haglund BJA, Tillgren PER, SvanstrÖM L, ÖStenson C-G, Holm L-E, et al. Effect and stage models in community intervention programmes; and the development of the Model for Management of Intervention Programme Preparation (MMIPP). Health Promot Int. 1996;11(2):143-56.

17. Pai S, Kapur RL. The burden on the family of a psychiatric patient: development of an interview schedule. Br J Psychiatry. 1981;138:332-5.

18. Lahariya C, Singhal S, Gupta S, Mishra A. Pathway of care among psychiatric patients attending a mental health institution in central India. Indian J Psychiatry. 2010;52(4):333-8.

19. Evans-Lacko S, London J, Japhet S, Rusch N, Flach C, Corker E, et al. Mass social contact interventions and their effect on mental health related stigma and intended discrimination. BMC Public Health. 2012;12:489.

20. Andersson CM, Bjaras GE, Ostenson CG. A stage model for assessing a community-based diabetes prevention program in Sweden. Health Promot Int. 2002;17(4):317-27. 